\title{
Why the CROWN Act of 2020 must be Passed into Law
}

\author{
Dr. Hilary R. Johnson-Lutz ${ }^{1}$ \\ ${ }^{1}$ Adjuct Faculty, University of Maryland Global Campus, Adelphi, Maryland, USA \\ *Correspondence: Dr. Hilary R. Johnson-Lutz, Email: hilaryjl@hotmail.com
}

\begin{abstract}
Black people are often burdened with having to decide between their natural hair and their employment. Media reports of late have uncovered that Black people of all ages and genders have faced the difficult choice of giving in to discrimination of their natural hair in school and at sporting events. The CROWN Act of 2020 was introduced as a response and a way forward in overcoming this burden. Furthermore, this legislation is an effort to educate the general public about the natural hair styles that are often seen as unkempt but are a proud aspect of Black culture. This paper will give the author's perspective of the significance of this legislation and personal experiences that have formed these views.
\end{abstract}

Keywords: CROWN act, Discrimination, Black hair, Legislation, Diversity, Inclusion, Natural hair, Black women, Women of color, Black culture

\section{ARTICLE INFORMATION}

Author(s): Dr. Hilary R. Johnson-Lutz

Received: 07 Oct, 2020; Accepted: 10 Nov, 2020; Article-in-Press: Volume

8, Issue 4 ;

e-ISSN: 2347-4696;

Paper Id: BMN-IJBMR-2020-11;

Citation: doi.org/10.37391/IJBMR.080403

Webpage-link: https://ijbmr.forexjournal.co.in/archive/volume-8/ijbmr-080403.html

\section{COMMENTARY}

"Hair plays a crucial role in identity formation that cannot be ignored. Giving voice to this issue sends a message of selfacceptance, which is necessary for well-being and overall health" [1].

On September 20, 2020, the US House of Representatives passed the Creating a Respectful and Open World for Natural Hair Act of 2020 or CROWN Act of 2020.

This bill prohibits discrimination based on a person's hair texture or hairstyle if that style or texture is commonly associated with a particular race or national origin. Of note, this bill specifically prohibits this type of discrimination in school and in the workplace. Furthermore, the bill emphasizes that no one should be deprived of equal rights under the law or subjected to prohibited practices based on their hair texture or style [2].

The CROWN Act initiative started with California State Senator, Holly Mitchell, who was inspired to pursue this initiative after seeing and hearing of numerous instances of hair discrimination suffered by black children and adults alike causing students to be forced from school and adults to lose their jobs [3]. After California Governor Newsom signed the CROWN Act into law in July of 2019, several states have since followed suit to include New York, Virginia and Florida.
It is hard to believe that in 2020 there is still a need for such legislation. However recent media reports clearly show there is a dire need to not only protect Black women in the workplace but Black people in general as it pertains to hair discrimination. A study conducted by Dove.com confirms that Black people experience clear bias when it comes to their hair. Black women are almost twice as likely to be sent home because of their hair and as a result more likely to change their natural hair to fit into appearance standards in the workplace. The study also revealed that Black people are "disproportionately burdened by policies and practices...that single them out" in a negative way [4].

\section{Why this legislation is important?}

The significance of the CROWN Act cannot be understated. This law will allow Black people to wear their hair in its natural state without fear. Fear of losing their jobs or being passed over for promotion. Black girls and boys can go to school without threat of being excluded from graduation ceremonies or having to make the tough choice between their hair and whether to forfeit an important wrestling match.

My personal experiences are just a drop in a deep well of too many examples of the discrimination that happens to many women of color, particularly African American women. We are often judged by our appearance and hair is a prominent aspect of our image. We live in a society where straight, blonde "Eurocentric" hair is considered beautiful and textured hair is considered unkempt and unappealing. African American women have fought for many years for the right to be ourselves in every area of our lives including the workplace. This means wearing our natural hair texture. However, we have become accustomed to "code switching" or adjusting to what is deemed "acceptable" when it comes to our hair. When we need to look "acceptable", we straighten our hair or don wigs that give us a more conservative appearance. 
My first encounter with hair discrimination happened when I was in the military in the late ' $80 \mathrm{~s}$. At that time, references to braided hairstyles were removed from the military dress and appearance regulations but restrictions against "faddish" hairstyles existed. I wore my hair in braids quite often because it was easy to maintain and allowed me to present what I deemed to be a neat and professional appearance. I knew that my hairstyle was not "faddish" but that did not stop others from challenging me on an almost daily basis. There was always some over-zealous Sergeant who thought that their interpretation of the regulation was correct but their reaction to me only highlighted a lack understanding about African American culture. I wore my braided styles frequently during my military career but consistently ran into those questioning whether my hair was against regulations. There was also this underlying concern about whether my style choices affected my opportunities for advancement within the military. With my hair being the source of so much debate felt like harassment and frankly, discouraged me from braided styles moving forward.

Fast forward through 20 years in the military where those challenges about my braids became less and less but that did not stop the micro-aggressions often in the form of over enthusiastic complements when I decided to straighten my hair or the "you should keep it that way" comments about my newly straightened hair. Currently, I wear my hair in locs and receive tremendous support from the Black community. I do wonder if my hair would pose a problem in a corporate setting. The CROWN Act passed into the law would give myself and countless other Black people peace of mind that our hair would not get in the way of our advancement.
Reading through numerous articles and viewing the viral social media posts on the topic of Black hair, I am struck by the all too common theme of Black people being required to meet standards of beauty and acceptance that don't apply to us and were never meant for us. I am also struck by the ominous mandate to fit in or be left out. Straight hair has historically been associated with higher social status and opportunities. Textured hair is often viewed as unattractive and undesirable. The CROWN Act has already changed that in so many ways. A Federal law is the next critical step. "It is crucial that as a society, we send the message to Black women and girls that they are worthy of admiration and respect in their natural states" [1].

\section{REFERENCES}

[1] Johnson, T. and Bankhead, T. (2014) Hair It Is: Examining the Experiences of Black Women with Natural Hair. Open Journal of Social Sciences, 2, 86-100.

[2] H.R.5309 - CROWN Act of 2020 (2019).

[3] C.R.O.W.N Research Study (2019).

[4] Mitchell, H. (2019). Why I'm leading the charge against natural hair discrimination in America.

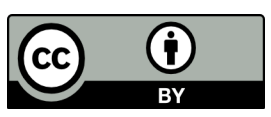

(C) 2020 by the Dr. Hilary R. Johnson-Lutz. Submitted for possible open access publication under the terms and conditions of the Creative Commons Attribution (CC BY) license (http://creativecommons.org/licenses/by/4.0/). 